\title{
Harmine and imipramine promote antioxidant activities in prefrontal cortex and hippocampus
}

\author{
Gislaine Z. Réus,' Roberto B. Stringari,, Bruna de Souza, ${ }^{2}$ Fabrícia Petronilho, ${ }^{2}$ Felipe Dal-Pizzol, ${ }^{2}$ Jaime E. Hallak, ${ }^{3}$ \\ Antônio W. Zuardi, ${ }^{3}$ José A. Crippa ${ }^{3}$ and João Quevedo',**

\begin{abstract}
'Laboratório de Neurociências; and ²Laboratório de Fisiopatologia Experimental; Instituto Nacional de Ciência e Tecnologia Translacional em Medicina (INCT-TM); Programa de Pós-Graduação em Ciências da Saúde; Unidade Acadêmica de Ciências da Saúde; Universidade do Extremo Sul Catarinense; Criciúma, SC Brazil; ${ }^{3}$ Departamento de Neurociências e Ciências do Comportamento; Instituto Nacional de Ciência e Tecnologia Translacional em Medicina (INCT-TM); Faculdade de Medicina de Ribeirão Preto; Universidade de São Paulo; Ribeirão Preto, SP Brazil
\end{abstract}

Key words: harmine, imipramine, reactive oxygen species, antioxidants activity, depression

\begin{abstract}
A growing body of evidence has suggested that reactive oxygen species (ROS) may play an important role in the physiopathology of depression. Evidence has pointed to the $\beta$-carboline harmine as a potential therapeutic target for the treatment of depression. The present study we evaluated the effects of acute and chronic administration of harmine $(5,10$ and $15 \mathrm{mg} / \mathrm{kg})$ and imipramine $(10,20$ and $30 \mathrm{mg} / \mathrm{kg})$ or saline in lipid and protein oxidation levels and superoxide dismutase (SOD) and catalase (CAT) activities in rat prefrontal cortex and hippocampus. Acute and chronic treatments with imipramine and harmine reduced lipid and protein oxidation, compared to control group in prefrontal cortex and hippocampus. The SOD and CAT activities increased with acute and chronic treatments with imipramine and harmine, compared to control group in prefrontal cortex and hippocampus. In conclusion, our results indicate positive effects of imipramine antidepressant and $\beta$-carboline harmine of oxidative stress parameters, increasing SOD and CAT activities and decreasing lipid and protein oxidation.
\end{abstract}

\section{Introduction}

A growing body of evidence has suggested that reactive oxygen species (ROS) may play an important role in the pathogenesis of neurological and psychiatric diseases including bipolar disorder and major depression..$^{1-9}$

ROS are free radicals or reactive anions/molecules containing oxygen atoms, such as hydroxyl radical, superoxide, hydrogen peroxide and peroxynitrite. ROS can cause cell damage by enzyme inactivation, lipid peroxidation and DNA modification..$^{10}$ Oxidative stress is well known to contribute to neuronal degeneration in the central nervous system (CNS) in the process of aging, as well, in neurodegenerative diseases.

Studies have consistently reported increase ROS in plasma on patients with major depression, especially with melancholia associated. ${ }^{11}$ Recent study showed evidences of oxidative stress in major depression as reflected in increased oxidative stress from frontal regions of patients compared to those of matched controls. ${ }^{12}$ Moreover we showed that rats subjected to chronic mild stress (CMS) had increase in superoxide production in hippocampus, prefrontal cortex and cortex brain and thiobarbituric acid reactive in cortex. ${ }^{5}$ In addition we demonstrated that stressed rats had increase protein (prefrontal, hippocampus, striatum and cortex) and lipid peroxidation (cerebellum and striatum), increase catalase (cerebellum, hippocampus, striatum and cortex) and a decrease in superoxide dismutase activity (prefrontal cortex, hippocampus, striatum and cortex). ${ }^{6}$ Additionally, oxidative stress is able to affect a number of synaptic functions, resulting in impaired neurotransmission. ${ }^{13}$

The monoamine hypothesis posits that depression is caused by decreased monoamine function in brain. ${ }^{14}$ Actually, the clinically-used antidepressants increase the extracellular concentrations of monoamines serotonin or norepinephrine either by inhibiting their reuptake from the synapse or by blocking their degradation by inhibiting monoamine oxidase..$^{15-17}$

Recently, studies have reported that $\beta$-carboline harmine possesses antidepressant properties. ${ }^{18-20}$ In fact, harmine interact with monoamine oxidase A (MAO-A) [21] and several cell-surface receptors, including serotonin receptor $2 \mathrm{~A}(5-\mathrm{HT} 2 \mathrm{~A})$, which are involved in antidepressant pharmacotherapy. ${ }^{22,23}$

Because of these findings, we designed the present study to investigate the effects of acute and chronic administration of harmine, imipramine (standard antidepressant) and saline on lipid and protein oxidation levels (markers of oxidative stress) and on superoxide dismutase (SOD) and catalase (CAT) activities (the major antioxidant enzymes) in rat brain. 


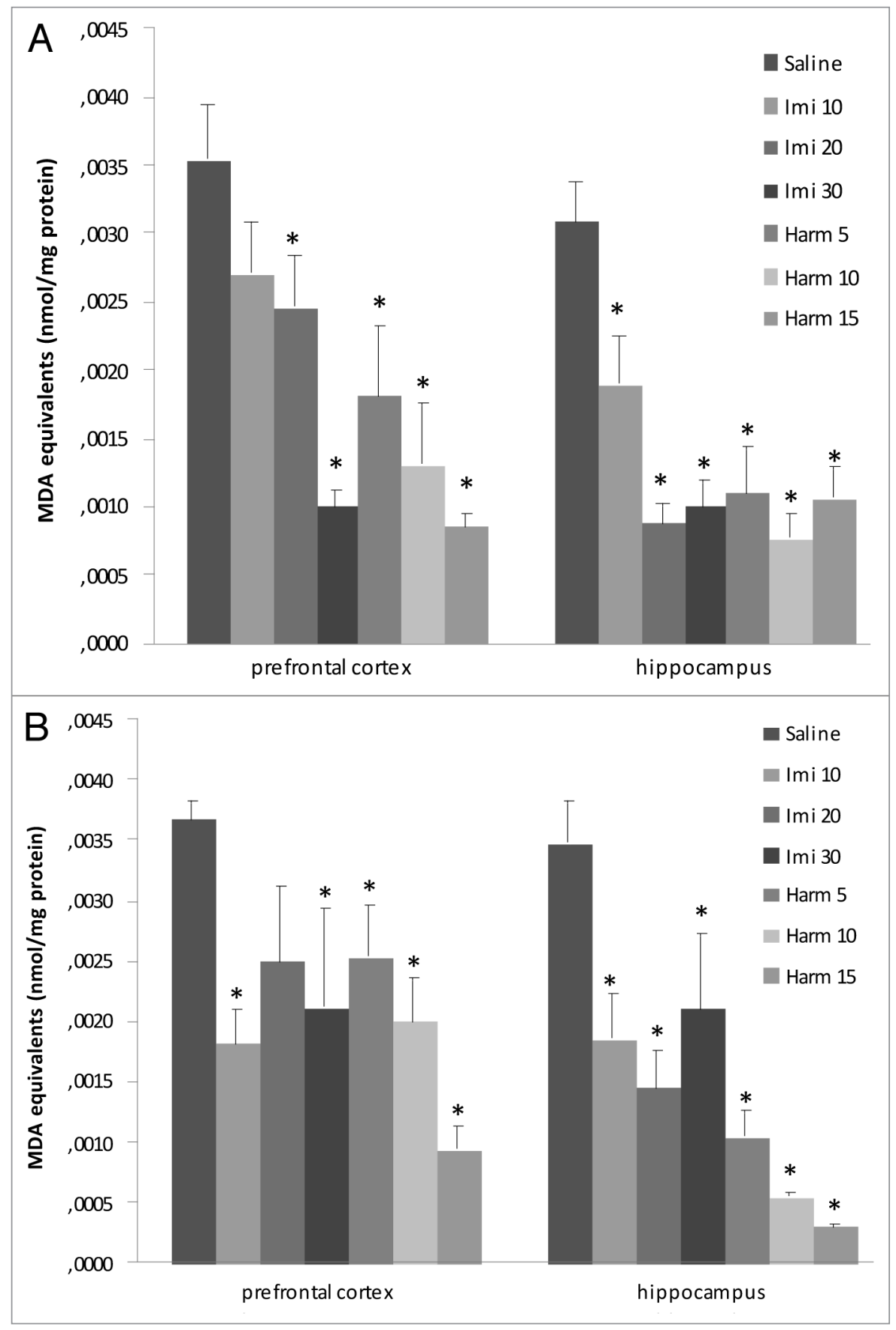

Figure 1. Effects of acute (A) and chronic (B) administration of imipramine $(10,20$ and $30 \mathrm{mg} / \mathrm{kg}$, i.p.) and harmine $(5,10$ and $15 \mathrm{mg} / \mathrm{kg}$, i.p.) on lipidic peroxidation in rat brain. The formation of TBARS decreased in prefrontal cortex and hippocampus after acute (A) and chronic (B) treatments with imipramine and harmine, compared to control group. Bars represent means \pm S.E.M. of 5 rats. ${ }^{*} p<0.05$ vs. saline according to ANOVA followed by Tukey post-hoc test.

\section{Results}

Thiobarbituric acid reactive species (TBARS). In the acute treatment (Fig. 1A), imipramine at doses of 20 and $30 \mathrm{mg} / \mathrm{kg}$ and harmine in all doses in prefrontal cortex and both imipramine and harmine in all doses in hippocampus decreased the lipid peroxidation $(\mathrm{F}=6.61 ; \mathrm{p}<0.05)$. Chronic treatment with imipramine at doses of 10 and $30 \mathrm{mg} / \mathrm{kg}$ and harmine in all doses reduced the lipid peroxidation in prefrontal cortex; and in all doses both harmine and imipramine decreased the lipid peroxidation in hippocampus $(F=10.44 ; \mathrm{p}<0.05$; Fig. 1B).

Protein carbonyls. As depicted in Figure $2 \mathrm{~A}$, acute administration of imipramine in all doses decreased protein carbonilation in prefrontal cortex and in hippocampus; however, acute treatment with harmine reduced protein carbonilation at doses of 5 and $15 \mathrm{mg} / \mathrm{kg}$ in prefrontal cortex and at dose of $15 \mathrm{mg} / \mathrm{kg}$ in hippocampus $(\mathrm{F}=2.18 ; \mathrm{p}<0.05)$. In the chronic treatment only the higher $(15 \mathrm{mg} / \mathrm{kg})$ of harmine and decreased the protein carbonilation in prefrontal cortex and hippocampus and imipramine at dose of $20 \mathrm{mg} / \mathrm{kg}$ decreases protein carbonilation in hippocampus $(\mathrm{F}=28.8 ; \mathrm{p}<0.05$; Fig. 2B $)$.

Catalase activity. The intraperitoneal acute treatment with imipramine in doses of 10 and $30 \mathrm{mg} / \mathrm{kg}$ and harmine in dose of $5 \mathrm{mg} / \mathrm{kg}$ increased catalase activity in prefrontal cortex; treatment with imipramine in all doses and harmine at doses of 5 and $10 \mathrm{mg} / \mathrm{kg}$ increased catalase activity in hippocampus $(F=4.9 ; p<0.05$; Fig. 3A). In the chronic treatment only imipramine at the dose of $20 \mathrm{mg} / \mathrm{kg}$ increased catalase activity in prefrontal cortex in comparison with control group ( $<<0.05$; Fig. 3B).

Superoxide dismutase activity. The superoxide dismutase activity increased in prefrontal cortex after acute treatment with imipramine at dose of $20 \mathrm{mg} / \mathrm{kg}$ and harmine at doses of 5 and $15 \mathrm{mg} / \mathrm{kg}$. In hippocampus the superoxide dismutase activity increased only harmine at dose of $5 \mathrm{mg} /$ $\mathrm{kg}(\mathrm{F}=2.45 ; \mathrm{p}<0.05$; Fig. 4A). Figure 4B showed the superoxide dismutase activity after chronic treatment with imipramine and harmine. Only the higher dose $(30$ $\mathrm{mg} / \mathrm{kg}$ ) of imipramine increased superoxide dismutase activity in prefrontal cortex; and only harmine at dose of $5 \mathrm{mg} /$ $\mathrm{kg}$ increased superoxide dismutase activity in hippocampus, compared to the control

\section{Discussion}

In the present study we showed that both acute and chronic treatments with imipramine and harmine reduce lipid and protein peroxidation and increased superoxide and catalase activities, 
compared to saline group in hippocampus and prefrontal cortex.

The hippocampus is one of several limbic structures that have been implicated in mood disorders. In addition, the hippocampus has connections with the prefrontal cortex, region that is more directly involved in emotion and cognition and thereby contributes to other major symptoms of mood disorders. ${ }^{24,25}$

The brain is particularly vulnerable to reactive oxygen species (ROS) production because it metabolizes $20 \%$ of total body oxygen and has a limited amount of antioxidant capacity. ${ }^{10}$

The oxidative stress in rat brain structures may play a role in the pathogenesis of anxiety ${ }^{26,27}$ and depression. ${ }^{28}$ In fact, our group very recently showed that rats subjected to chronic mild stress (CMS) had an increase in superoxide production and thiobarbituric acid reactive protein and lipid peroxidation and catalase activity, and a decrease in superoxide dismutase activity in rat brain., 50 Moreover, a previous study using an animal model of repeated restraint stress showed that this model induced an increase in TBARS levels in hippocampus. ${ }^{29}$ In another study, it was demonstrated that animal model of immobilization stress causes significant increases in lipid peroxidation, which was found in cerebral cortex, cerebellum and hippocampus compared to the unstressed controls; significant increases in levels of protein oxidation were also found in cortex, hypothalamus and striatum; oxidative nuclear DNA damage increased after stress in all brain regions, although only the cerebral cortex showed a significant increase. ${ }^{30}$ In humans elevated ROS in plasma of patients with major depression, especially in those with melancholic type and increased oxidative stress in depressive woman, was demonstrated. ${ }^{3,11}$ Additionally, Galecki et al..$^{31}$ demonstrated that combined fluoxetine antidepressant and acetylsalicylic acid therapy improvement of oxidative stress parameters in patients with depression. Moreover, exogenous administration of 5-hydroxytryptophan prevented depletion of serotonin concentration and antioxidant status induced by $\mathrm{p}$-chlorophenylalanine in rat brain. ${ }^{32}$

In this study we showed that acute and chronic treatment with imipramine antidepressant improvement of oxidative stress
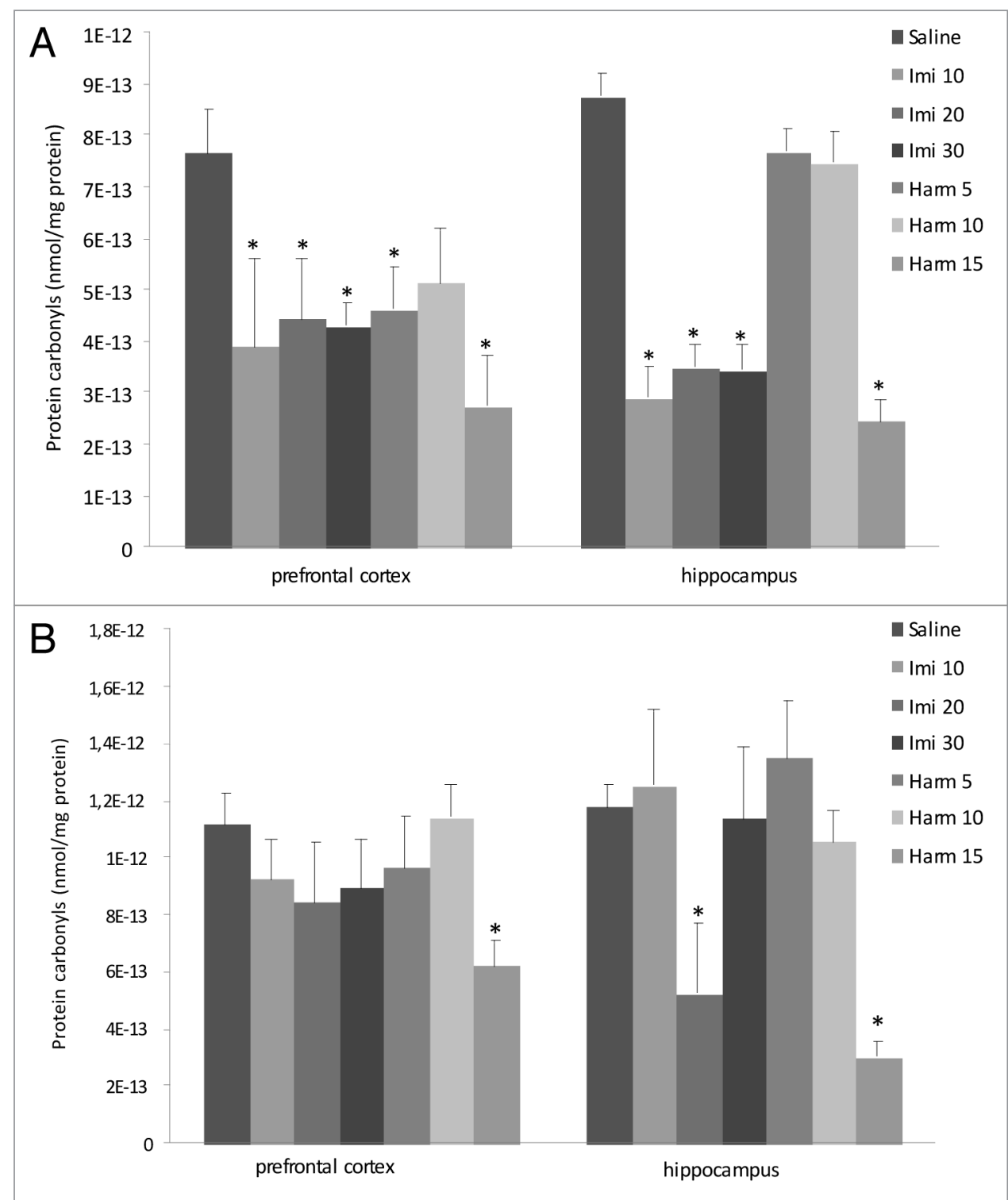

Figure 2. Effects of acute (A) and chronic (B) administration of imipramine $(10,20$ and $30 \mathrm{mg} / \mathrm{kg}$, i.p.) and harmine $(5,10$ and $15 \mathrm{mg} / \mathrm{kg}$, i.p.) on protein peroxidation in rat brain. The carbonyl groups decreased in prefrontal cortex and hippocampus after acute treatment (A) with imipramine and harmine and in prefrontal cortex and hippocampus with harmine and in hippocampus with imipramine after chronic treatment (B), compared to control group. Bars represent means \pm S.E.M. of 5 rats. ${ }^{*} p<0.05$ vs. saline according to ANOVA followed by Tukey post-hoc test.

parameters in rat brain. Several studies have reported the role of imipramine in oxidative stress parameters. In fact, imipramine treatment reversed the lipid peroxidation in brain of Sprague Dawley rats induced by chronic ozone. ${ }^{33}$ In addition, acute treatment with imipramine $(10$ and $20 \mathrm{mg} / \mathrm{kg}$ ) and venlafaxine (5 and $10 \mathrm{mg} / \mathrm{kg}$ ) reversed immobilized stress-induced behavioral and biochemical (such as malondialdehyde level, nitrite, glutathione and catalase enzyme) alterations in mice; in some study was showed that l-NAME and/or methylene blue potentiated the effect of both imipramine and venlafaxine, suggesting the involvement of nitric oxide mechanism in the protective effect of imipramine and venlafaxine. ${ }^{34}$ In other hand, acute 


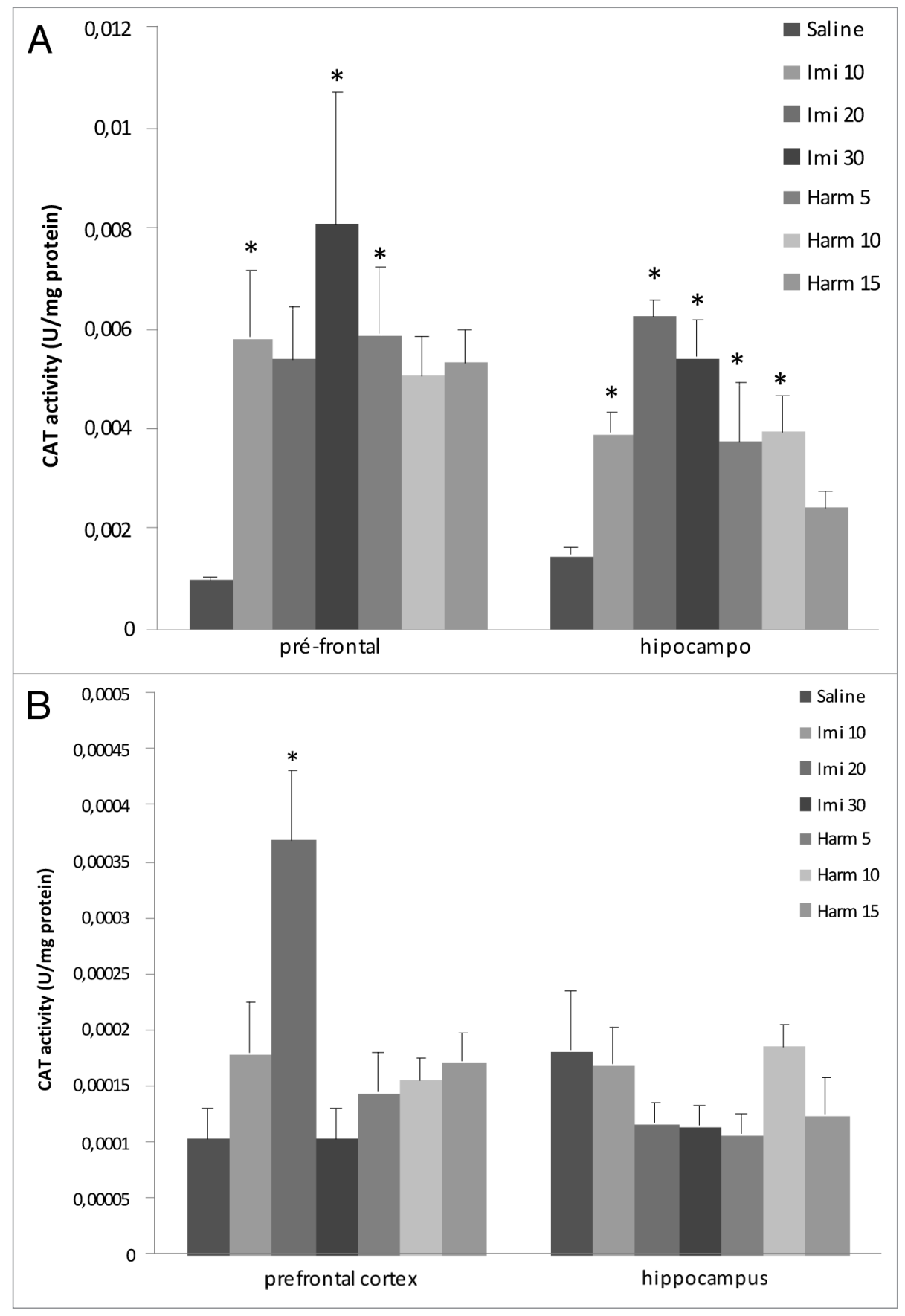

Figure 3. Effects of acute (A) and chronic (B) administration of imipramine $(10,20$ and $30 \mathrm{mg} / \mathrm{kg}$, i.p.) and harmine $(5,10$ and $15 \mathrm{mg} / \mathrm{kg}$, i.p.) on catalase activity in rat brain. The catalase activity increased in prefrontal cortex after acute (A) and chronic (B) treatments with imipramine and in prefrontal cortex and hippocampus after chronic treatment (B) with harmine, compared to control group. Bars represent means \pm S.E.M. of 5 rats. ${ }^{*} p<0.05$ vs. saline according to ANOVA followed by Tukey post-hoc test.

seizure activity promotes lipid peroxidation and increased nitrite levels in frontal cortex and striatum. ${ }^{35}$ Imipramine (10 and 20 $\mathrm{mg} / \mathrm{kg}$ ) and trazodone $(5$ and $10 \mathrm{mg} / \mathrm{kg}$ ) antidepressants restored depleted reduced glutathione levels and catalase activity and attenuated raised lipid peroxidation and nitrite concentrations in mice sleep-deprived, compared to untreated sleep-deprived. ${ }^{36}$
Nevertheless, a significant recovery in the activities of superoxide dismutase, catalase, glutathione S-transferase, glutathione redutase and glutathione levels by fluoxetine, imipramine and venlafaxine treatments following a restraint stressinduced decline of these parameters, and accumulated lipid peroxidation product malondialdehyde and protein carbonyl contents in stressed animal were normalized by some antidepressants. ${ }^{37}$

Moreover, we also demonstrated that $\beta$-carboline harmine improvement of oxidative stress parameters. Kim et al. ${ }^{38}$ reported that harmine has a role in oxidative stress. In fact, they showed that $\beta$-carbolines (harmaline, harmalol and harmine) attenuated the dopamine or 6-hydroxydopamine-induced alteration of brain mitochondrial and synaptosomal functions, and viability loss in PC12 cells, by a scavenging action on reactive oxygen species and inhibition of thiol oxidation. ${ }^{38}$

Our group has shown antidepressant properties of harmine. ${ }^{19,20}$ In fact, treatment with harmine at doses of 10 and $15 \mathrm{mg} / \mathrm{kg}$ and imipramine at doses of 20 and $30 \mathrm{mg} / \mathrm{kg}$ decreased immobility time of rats, and increased both climbing and swimming time of rats compared to saline group, and were also showed that imipramine and harmine did not affect spontaneous locomotor activity in the open-field test. ${ }^{19}$ In this study were demonstrated that harmine $(15 \mathrm{mg} / \mathrm{kg})$ increased brain-derived neurotrophic factor (BDNF) protein levels in rat hippocampus. In other study from our group showed that harmine reverted stress parameters induced by chronic mild stress model..$^{20}$ In addition, Farzin et al. ${ }^{18}$ demonstrated that treatment with harmane, norharmane and harmine dose-dependently reduced the immobility time in the mouse forced swimming test. These studies suggest antidepressant-like effects of harmine could be due to interactions of harmine with several receptor systems involved in the modulation of behavioral and molecular actions of antidepressants.

In conclusion, considering that oxidative stress is probably involved in the pathophysiology of depression, the modulation by antidepressants could be an important mechanism of action of these drugs and harmine could be a positive effect in oxidative stress parameters, which may play a role in the pathogenesis of depression. 


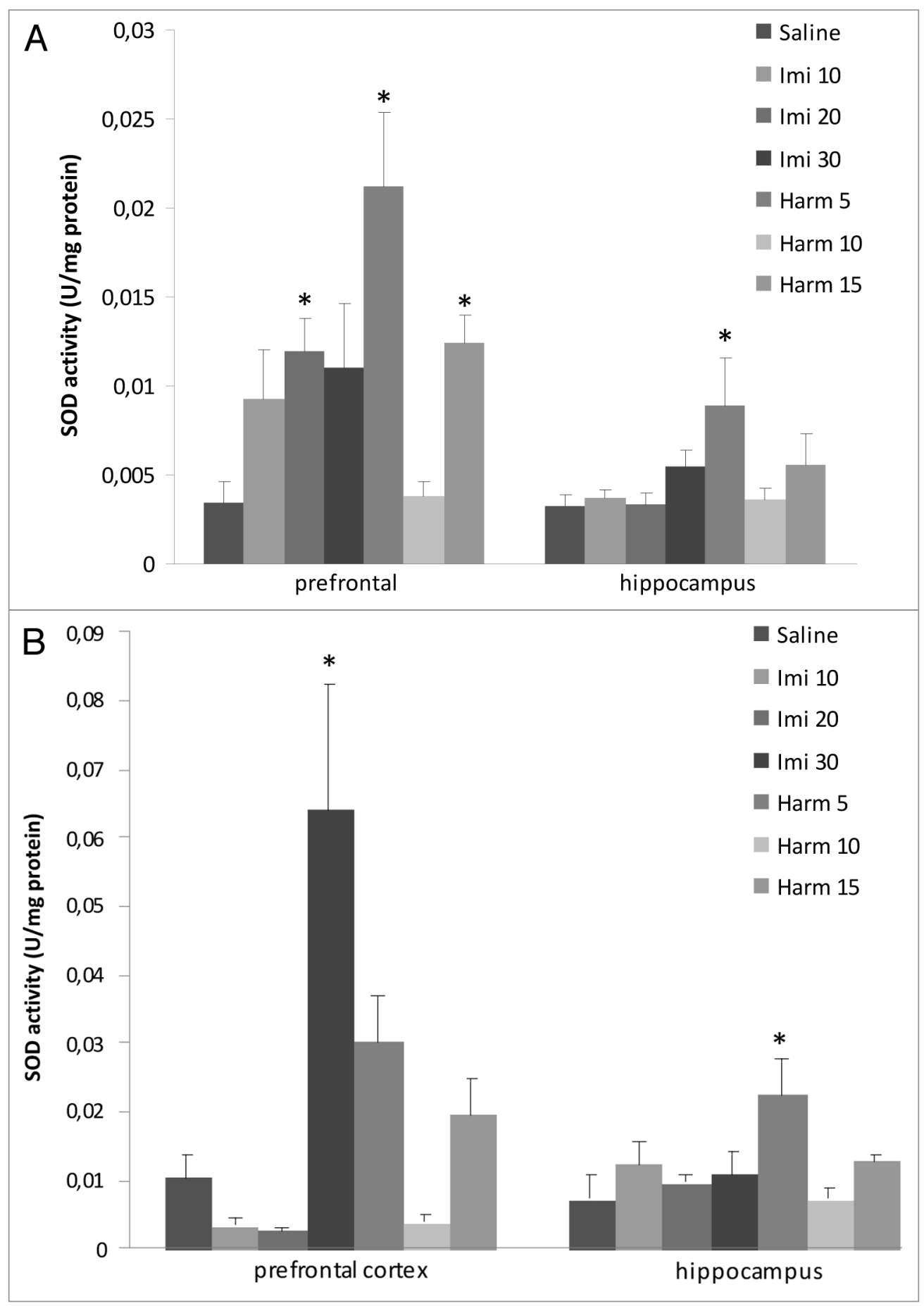

Figure 4. Effects of acute (A) and chronic (B) administration of imipramine (10, 20 and $30 \mathrm{mg} / \mathrm{kg}$, i.p.) and harmine (5, 10 and $15 \mathrm{mg} / \mathrm{kg}$, i.p.) on superoxide dismutase activity in rat brain. The superoxide dismutase activity increased after acute treatment $(\mathrm{A})$ in prefrontal cortex with imipramine and harmine and in hippocampus with harmine and after chronic treatment with imipramine in prefrontal cortex and harmine in hippocampus, compared to control group. Bars represent means \pm S.E.M. of 5 rats. ${ }^{*} p<0.05$ vs. saline according to ANOVA followed by Tukey post-hoc test.

\section{Materials and Methods}

Animals. Male Adult Wistar rats (60 days old) were obtained from UNESC (Universidade do Extremo Sul Catarinense, Criciúma, Brazil) breeding colony. They were housed five per cage with food and water available ad libitum and were maintained on a $12 \mathrm{~h} \mathrm{light/dark} \mathrm{cycle} \mathrm{(lights} \mathrm{on} \mathrm{at} \mathrm{7:00} \mathrm{AM).} \mathrm{All} \mathrm{experimental}$ procedures involving animals were performed in accordance with the NIH Guide for the Care and Use of Laboratory Animals and the Brazilian Society for Neuroscience and Behavior $(\mathrm{SBNeC})$ recommendations for animal care and with approval by local Ethics Committee under protocol number 325/2008. 
Drugs and treatments. Harmine was obtained from THCPharm/STI-Pharm (Frankfurt, Germany) and imipramine, the standard antidepressant, from Novartis Pharmaceutical Industry (Criciúma, Brazil). Different groups of rats $(\mathrm{n}=5$ each) were administered intraperitoneally (i.p.) with saline or different doses of harmine $(5,10$ and $15 \mathrm{mg} / \mathrm{kg})$ or imipramine $(10,20$ and 30 $\mathrm{mg} / \mathrm{kg}$ ) once only (acute treatment) or once a day for 14 days (chronic treatment). ${ }^{20-23,39}$ Imipramine and harmine were dissolved in saline immediately before the injections. All treatments were administered in a volume of $1 \mathrm{~mL} / \mathrm{kg}$. After $60 \mathrm{~min}$ acute and chronic treatment, the animals were killed by decapitation. The hippocampus and prefrontal cortex were quickly isolated by hand dissection using a magnifying glass and a thin brush, dissection was based on histological distinctions described by Paxinos and Watson..$^{40}$ Samples were stored at $70^{\circ} \mathrm{C}$ for subsequent analysis of oxidative stress.

Oxidative stress parameters. In order to assess oxidative damage, was measured the formation of thiobarbituric acid reactive species (TBARS) during an acid-heating reaction, as previously described by Esterbauer and Cheeseman. ${ }^{41}$ The samples were mixed with $1 \mathrm{~mL}$ of trichloroacetic acid (TCA) $10 \%$ and $1 \mathrm{~mL}$ of thiobarbituric acid $0.67 \%$ and were then heated in a boiling water bath for $15 \mathrm{~min}$. TBARS were determined by the absorbance at $535 \mathrm{~nm}$. Oxidative damage to proteins was measured by the quantification of carbonyl groups based on the reaction with dinitrophenylhidrazine (DNPH), as previously described by Levine et al. ${ }^{42}$ Proteins were precipitated by the addition of $20 \%$

\section{References}

1. Frey BN, Valvassori SS, Réus GZ, Martins MR, Petronilho FC, Bardini K, et al. Changes in antioxidant defense enzymes after $\mathrm{d}$-amphetamine exposure: implications as an animal model of mania. Neurochem Res 2006; 31:699-703

2. Frey BN, Valvassori SS, Réus GZ, Martins MR, Petronilho FC, Bardini K, et al. Effects of lithium and valproate on amphetamine-induced oxidative stress generation in an animal model of mania. J Psychiatry Neurosci 2006; 31:326-32.

3. Kodydková J, Vávrová L, Zeman M, Jirák R, Macášek J, Sta ková B, et al. Antioxidative enzymes and increased oxidative stress in depressive women. Int J Neuropsychopharmacol 2008; 11:851-76.

4. Kunz M, Gama CS, Andreazza AC, Salvador M, Ceresér KM, Gomes FA, et al. Elevated serum superoxide dismutase and thiobarbituric acid reactive substances in different phases of bipolar disorder and in schizophrenia. Prog Neuropsychopharmacol Biol Psychiatry 2008; 32:1677-81.

5. Lucca G, Comim CM, Valvassori SS, Réus GZ, Vuolo F, Petronilho F, et al. Increased oxidative stress in submitochondrial particles into the brain of rats submitted to the chronic mild stress paradigm. J Psych Res 2009; 43:864-9.

6. Lucca G, Comim CM, Valvassori SS, Réus GZ, Vuolo F, Petronilho F, et al. Effects of chronic mild stress on the oxidative parameters in the rat brain. Neurochem Int 2009; 54:358-62.

7. Ng F, Berk M, Dean O, Bush AI. Oxidative stress in psychiatric disorders: evidence base and therapeutic implications. Int J Neuropsychopharmacol 2008; 11:851-76.

8. Riegel RE, Valvassori SS, Elias G, Réus GZ, Steckert AV de Souza B, et al. Animal model of mania induced by ouabain: Evidence of oxidative stress in submitochondrial particles of the rat brain. Neurochem Int 2009; 55:491-5. 1999; 222:236-45. 151:145-50. 69:2529-37. 6:241-6. 1997; 54:597-606. 2002; 34:13-25 trichloroacetic acid and were redissolved in $\mathrm{DNPH}$; the absorbance was read at $370 \mathrm{~nm}$. To determine CAT activity, the brain tissue was sonicated in $50 \mathrm{mmoL} / \mathrm{L}$ phosphate buffer $(\mathrm{pH} 7.0)$, and the resulting suspension was centrifuged at $3,000 \mathrm{~g}$ for 10 min. The supernatant was used for enzyme assay. CAT activity was measured by the rate of decrease in hydrogen peroxide absorbance at $240 \mathrm{~nm} .{ }^{43}$ SOD activity was assayed by measuring the inhibition of adrenaline auto-oxidation, as previously described by Bannister and Calabrese. ${ }^{44}$ All biochemical measures were normalized to the protein content, with bovine albumin as standard. ${ }^{45}$

Statistical analysis. All data are presented as mean \pm S.E.M. In the assessment of oxidative stress parameters were determined by one-way ANOVA, followed by Tukey post-hoc test when ANOVA was significant; $p$ values less than 0.05 were considered to be statistical significant.

\section{Acknowledgements}

This study was supported in part by grants from 'Conselho Nacional de Desenvolvimento Científico e Tecnológico' (CNPqBrazil-J.Q., JAC, A.W.Z. J.E.H.), from 'Fundação de Amparo à Pesquisa do Estado de São Paulo fellowship' (FAPESP-J.A.C., A.W.Z. J.E.H.), FAPESC (J.Q.), and from the Instituto Cérebro e Mente (J.Q.) and UNESC (J.Q. and F.D.P.). J.Q., F.D.P., J.A.C. and A.W.Z. are recipients of CNPq (Brazil) Productivity fellowships. G.Z.R. is holder of a FAPESC/CAPES studentship. This study was also sponsored by THC-Pharm (Frankfurt, Germany) and STI-Pharm (UK) who kindly provided harmine.
9. Wood SJ, Yücel M, Pantelis C, Berk M. Neurobiology of schizophrenia spectrum disorders: the role of oxidative stress. Ann Acad Med Singapore 2009; 38:396-406.

10. Floyd RA. Antioxidants, oxidative stress and degenerative neurological disorders. Proc Soc Exp Biol Med

11. Bilici M, Efe H, Koroglu MA, Uydu HÁ, Bekaroglu $\mathrm{M}$, Deger O. Antioxidative enzyme activities and lipid peroxidation in major depression: alterations by antidepressant treatments. J Affect Disorders 2001; 64:43-51.

12. Michel TM, Frangou S, Thiemeyer D, Camara $S$, Jecel J, Nara K, et al. Evidence for oxidative stress in the frontal cortex in patients with recurrent depressive disorder-a postmortem study. Psychiat Res 2007;

13. Tretter L, Chinopoulos C, Adam-Vizi V. Enhanced depolarization-evoked calcium signal and reduced $[\mathrm{ATP}] /[\mathrm{ADP}]$ ratio are unrelated events induced by oxidative stress in synaptosomes. J Neurochem 1997;

14. Berton O, Nestler EJ. New approaches to antidepressant drug discovery: beyond monoamines. Nature Rev Neurosc 2006; 7:137-45.

15. Castrén E. Is mood chemistry? Nat Rev Neurosc 2005;

16. Duman RS, Heninger GR, Nestler EJ. A molecular and cellular theory of depression. Arch Gen Psychiatry

17. Nestler EJ, Barrot M, DiLeone RJ, Eisch AJ, Gold SJ, Monteggia LM. Neurobiology of depression. Neuron

18. Farzin D, Mansouri N. Antidepressant-like effect of harmane and other $\beta$-carbolines in the mouse forced swim test. Eur Neuropsychopharmacol 2006; 16:324-8.

19. Fortunato JJ, Réus GR, Kirsch TR, Stringari RB, Fries GR, Kapczinski F, et al. Effects of Beta-carboline harmine on behavioural and physiological parameters observed in the chronic mild stress model: further evidence of antidepressant properties. Brain Res Bull 2010; 81:491-6.

20. Fortunato JJ, Réus GZ, Kirsch TR, Stringari RB, Stertz L, Kapczinski F, et al. Acute harmine administration induces antidepressive-like effects and increases BDNF levels in the rat hippocampus. Prog Neuropsychopharmacol Biol Psychiatry 2009; 33:1425-30.

21. Kim H, Sablin SO, Ramsay RR. Inhibition of monoamine oxidase A by beta-carboline derivatives. Arch Biochem Biophys 1997; 337:137-42.

22. Glennon RA, Dukat M, Grella B, Hong S, Costantino $\mathrm{L}$, Teitler $\mathrm{M}$, et al. Binding of beta-carbolines and related agents at serotonin $(5-\mathrm{HT}(2)$ and 5-HT(1A)), dopamine $(\mathrm{D}(2))$ and benzodiazepine receptors. Drug Alcohol Depend 2000; 60:121-32.

23. Preskorn SH, Baker B, Kolluri S, Menniti FS, Krams $\mathrm{M}$, Landen JW. An innovative design to establish proof of concept of the antidepressant effects of the NR2B subunit selective N-Methyl-D-Aspartate antagonist, CP-101,606, in patients with treatment-refractory major depressive disorder. J Clin Psychopharmacol 2008; 28:631-7.

24. Duman RS, Monteggia LM. A Neurotrophic Model for Stress-Related Mood Disorders. Biol Psychiatry 2006; 59:1116-27.

25. Hall J, Whalley HC, Marwick K, McKirdy J, Sussmann J, Romaniuk L, et al. Hippocampal function in schizophrenia and bipolar disorder. Psychol Med 2009; 7:1-10.

26. Maiese K. High anxiety: recognizing stress as the stressor. Oxid Med Cell Longev 2009; 2:61-2.

27. Bouayed J, Rammal H, Soulimani R. Oxidative stress and anxiety: relationship and cellular pathways. Oxid Med Cell Longev 2009; 2:63-7. 
28. Eren I, Naziro lu M, Demirdas A, Celik O, U uz AC, Altunbasak A, et al. Venlafaxine modulates depressioninduced oxidative stress in brain and medulla of rat Neurochem Res 2007; 32:497-505.

29. Fontella FU, Siqueira IR, Vasconcellos AP, Tabajara AS, Netto CA, Dalmaz C. Repeated restraint stress induces oxidative damage in rat hippocampus. Neurochem Res 2005; 30:105-11.

30. Liu J, Wang X, Shigenaga MK, Yeo HC, Mori A, Ames $\mathrm{BN}$. Immobilization stress causes oxidative damage to lipid, protein and DNA in the brain of rats. FASEB J 1996; 10:1532-8.

31. Gałecki P, Szemraj J, Bienkiewicz M, Zboralski K, Gałecka E. Oxidative stress parameters after combined fluoxetine and acetylsalicylic acid therapy in depressive patients. Hum Psychopharmacol Clin Exp 2009; 24:277-86

32. Muñoz-Castañeda JR, Montilla P, Padillo FJ, Bujalance I, Muñoz MC, Muntané J, et al. Role of serotonin in cerebral oxidative stress in rats. Acta Neurobiol Exp (Wars) 2006; 66:1-6

33. Mokoena ML, Harvey BH, Oliver DW, Brink CB. Ozone modulates the effects of imipramine on immobility in the forced swim test and nonspecific parameters of hippocampal oxidative stress in the rat. Metab Brain Dis 2010; 25:125-33.
34. Kumar A, Garg R, Gaur V, Kumar P. Nitric oxide mechanism in protective effect of imipramine and venlafaxine against acute immobilization stress-induced behavioral and biochemical alteration in mice. Neurosci Lett 2009; 467:72-5.

35. Júnior HV, de França Fonteles MM, Mendes de Freitas R. Acute seizure activity promotes lipid peroxidation, increased nitrite levels and adaptative pathways against oxidative stress in the frontal córtex and striatum. Oxid Med Cell Longev 2009; 2:130-7.

36. Kumar A, Garg R. Possible role of trazodone and imipramine in sleep deprivation-induced anxiety-like behavior and oxidative damage in mice. Methods Fin Exp Clin Pharmacol 2009; 31:383-7.

37. Zafir A, Ara A, Banu N. Invivo antioxidant status: a putative target of antidepressant action. Prog Neuropsychopharmacol Biol Psychiatry 2009; 33:220-8.

38. Kim DH, Jang YY, Han ES, Lee CS. Protective effect of harmaline and harmalol against dopamineand 6-hydroxydopamine-induced oxidative damage of brain mitochondria and synaptosomes and viability loss of PC12 cells. Euro J Neurosci 2001; 13:1861-72.
39. Garcia LB, Comim CM, Valvassori SS, Réus GZ, Barbosa LM, Andreazza AC, et al. Acute administration of ketamine induces antidepressant-like effects in the forced swimming test and increases BDNF levels in the rat hippocampus. Prog Neuropsychopharmacol Biol Psych 2008; 32:140-4

40. Paxinos G, Watson C. The rat brain: stereotaxic coordinates. Second Ed. Australia: Academic Press 1986.

41. Esterbauer H, Cheeseman KH. Determination of aldehydic lipid peroxidation products: malonaldehyde and 4-hydroxynonenal. Methods Enzymo 1990; 186:407-21.

42. Levine RL, Williams JA, Stadtman ER, Shacter E. Carbonyl assays for determination of oxidatively modified proteins. Methods Enzymol 1994; 233:346-57.

43. Aebi H. Catalase in vitro. Methods Enzymol 1984; 105:121-6.

44. Bannister JV, Calabrese L. Assays for superoxide dismutase. Methods Biochem Anal 1987; 32:279-312

45. Lowry $\mathrm{OH}$, Rosebrough NJ, Farr AL, Randall RJ. Protein measurement with the Folin phenol reagent. Biol Chem 1951; 193:265-75. 


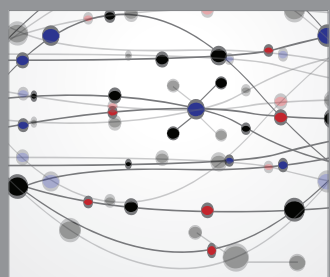

The Scientific World Journal
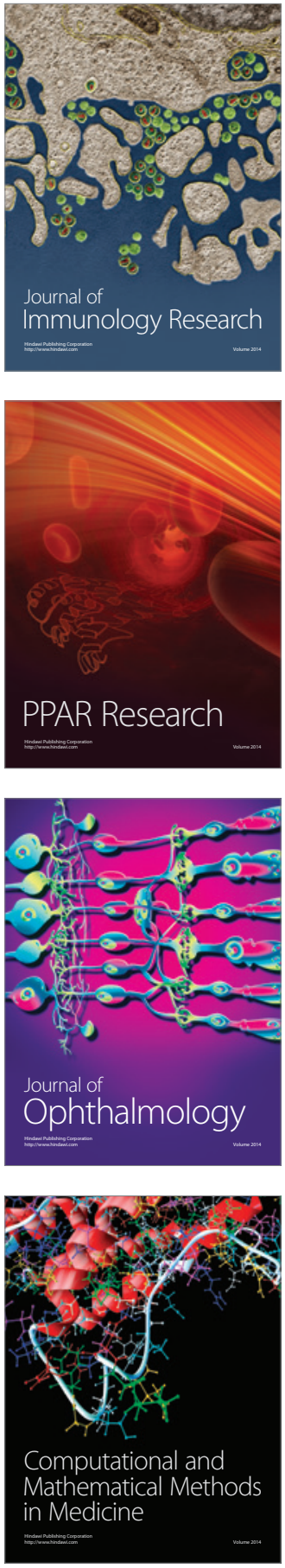

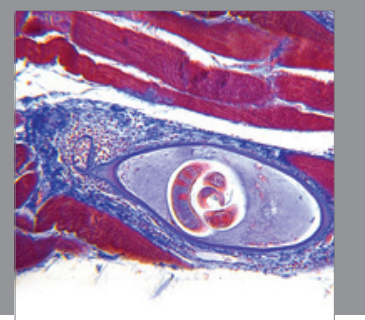

Gastroenterology

Research and Practice
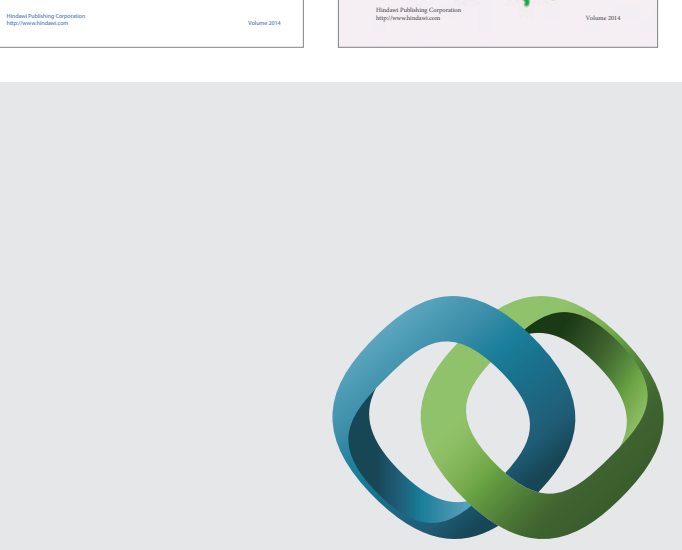

\section{Hindawi}

Submit your manuscripts at

http://www.hindawi.com
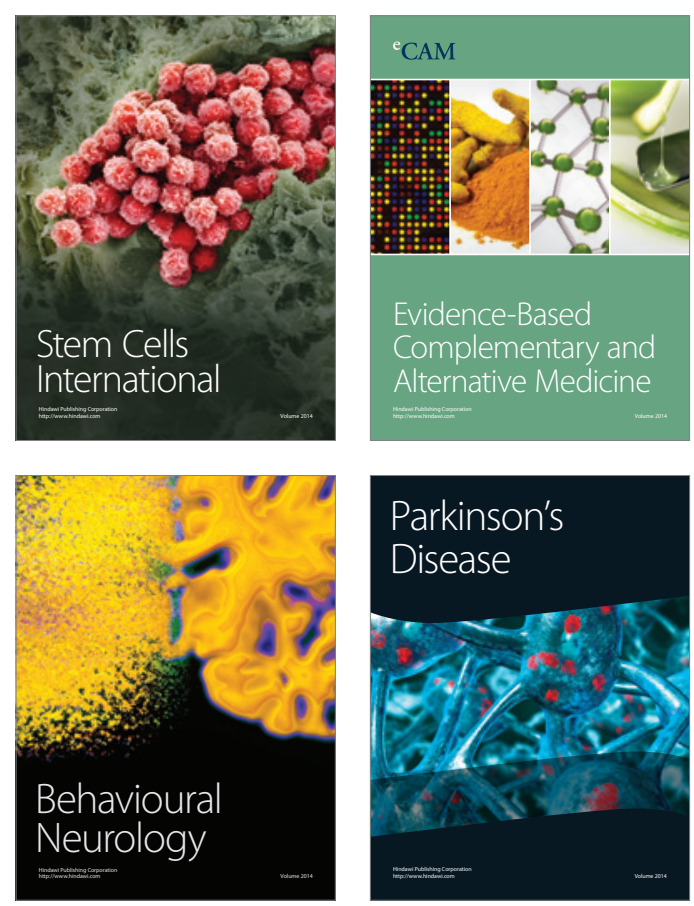

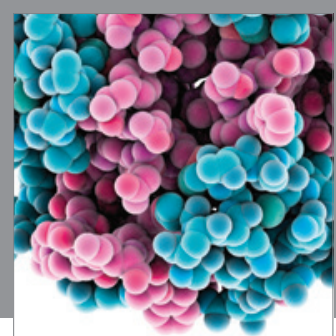

Journal of
Diabetes Research

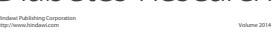

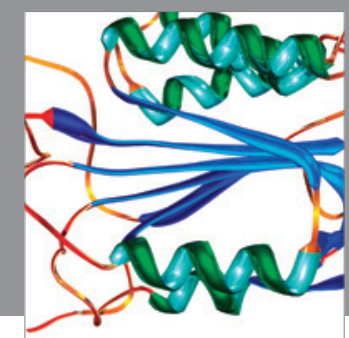

Disease Markers
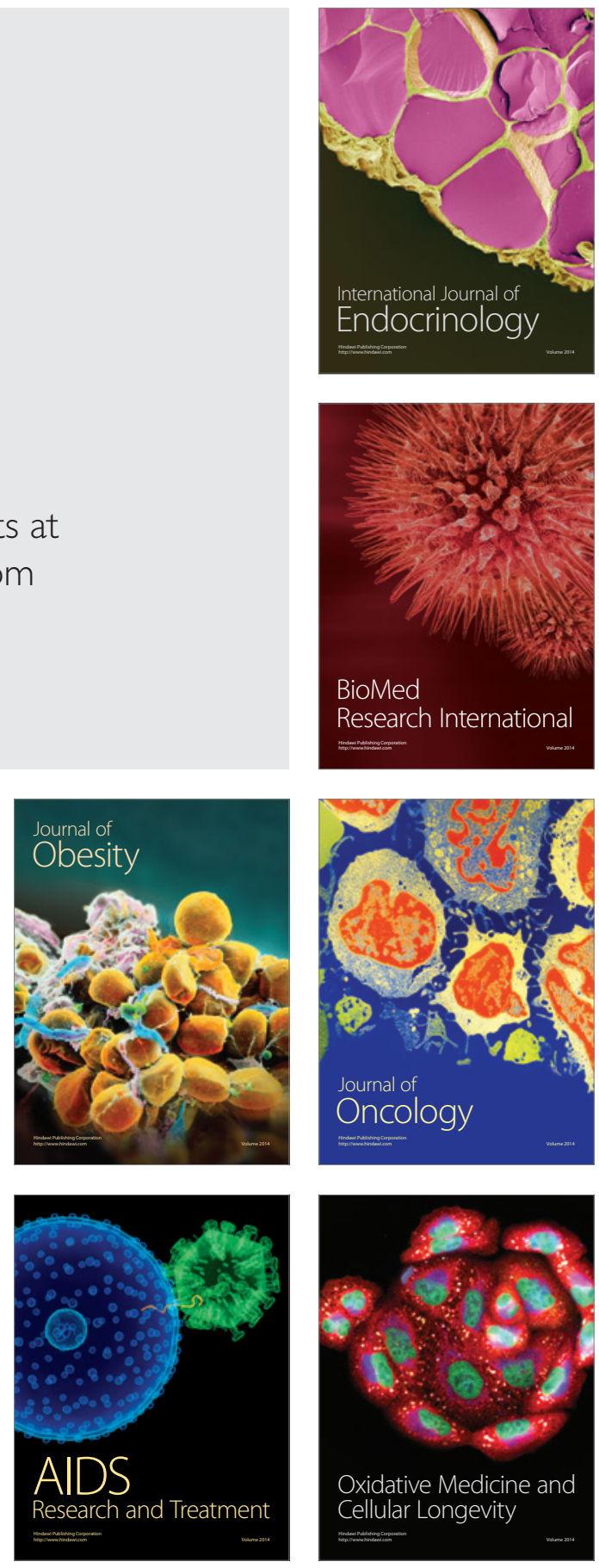